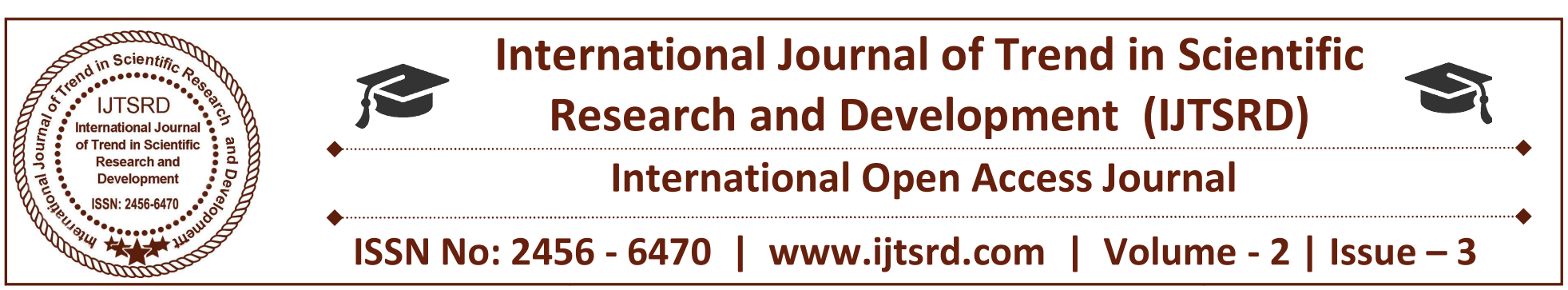

\title{
ERP System for Soft Commodities
}

\author{
Saloni Shrimali, Aayushi Jain, Komal Adhav \\ Department of Computer Engineering, MET's Institute of Engineering, Nashik, Maharashtra, India
}

\begin{abstract}
The efficiency of marketing for soft commodities in India has been of significant concern in the recent years. Out of 370 million tons of fruit production in the world, India accounts for 30 million tons. Over the last decade, the area under horticulture grew by about $2.7 \%$ per annum and annual production increased by $7 \%$.
\end{abstract}

With today's era of digitization, the dealer, farmers, wholesaler of soft commodities are maintaining the Expense Management, Accounting, Purchase Management, etc. manually and which is time consuming with no transparency, this in return creating major problem for trading.

So, focusing on the above problem definition, we propose an ERP based system for major category of people involved in soft commodities, which has merits over current system in practice. The proposed system will have features like SMS facility, managing wholesale business. Managing orders/sale, Purchases with accounting facility along with various business report formats based on individual requirements. This will help stakeholders to understand trading details of their soft commodities.

Keywords: Data Mining, Enterprise Resource Planning, Business Techniques, Expense management, Purchase management, Sales and Marketing

\section{INTRODUCTION}

\section{Data Mining:}

Data mining is the process of analyzing data from different perspectives and summarizing it into useful information. The opinions of stakeholders greatly influence decision making of individuals as well as communities. It is the process of analyzing large amounts of data warehouse for useful information which makes use of artificial intelligence techniques, neural networks and advanced statistical tools[4]. Data mining has been used in numerous areas, which include both private as well as public sectors. Now a days use of data mining is expanding everywhere. It is a new technology, which helps organizations to process data through algorithms to uncover meaningful patterns and correlations from large databases that may otherwise be not possible with standard analysis and reporting. Data mining tools can understand the business better and also improve future performance through predictive analytics and make them proactive and allow knowledge driven decisions. It finds its application in market analysis and management like for example : customer relationship management, cross selling, market segmentation. It can also be used in risk analysis and management for forecasting, quality control etc. Sentiment analysis is often conducted at one of the three levels: the document level, sentence level, or attribute level.

Document level : In this approaches whole document is considered as a single entity and the analysis approaches in applied on the whole document. The result generated in document level sometimes not appropriate[11].

Sentence level: In the sentence level approaches every sentence is considered as an entity and analysis approaches is applied on individual sentence then their result is summarized to provide the overall result of the document[10].

Aspect level: Phrase-level opinion mining is also known as aspect based opinion mining. It performs 
fine grained analysis directly looks at the opinion. The goal of this level of analysis is to discover sentiments on aspects of items[9].

Here we are working on aspect level, as we are dealing to achieve result of different aspects or modules individually and not the entire system as the whole.

The proposed ERP system for soft commodities, soft commodities include the entire agricultural product such as fruits, vegetables and grains. This system is beneficial for three end users, i.e. farmer, dealer and customer. This system is the best platform for them to gain accuracy in trading, generating bills, maintaining records, etc.

As there are many such systems but, no system provide us with the trading between all the three users farmer, dealer and customers. We are providing an image recognition feature, were we can recognize the quality of the product for sale and purchase.

\section{LITERATURE SURVEY}

ERP stands for Enterprise Resource Planning. ERP is an enterprise-wide information system that facilitates the flow of information and coordinates all resources and activities within the business organization.

Red Apple Sabzi Mandi ERP Software, which performs buying and selling of goods. This software manages buying, selling, ordering and accounting in such a way that it helps the dealer to make the balance sheet about their products in a perfect manner and helps them to make dealing of their products and perform the trading[2].But it mainly deals with the customers of fruits rather than all soft commodities.

Aritmos - Sage X3 for fruits and vegetables ERP solution, management software, which is based on agriculture based data, farm management, purchasing, selling and commissions[5].This ERP mainly focuses on supplying the products to the industries as well as companies.

And our proposed system will overcome the already existing modules because of its features involving the communication of dealers with the farmers as well as customers too in order to maintain their trading in a proper flow.
An ERP system is a standardized software package that combines functionality of multiple business functions into one integrated system.

Characteritics:

1. Multi-functional

2. Integrated

3. Business Critical

\section{PROPOSED SYSTEM}

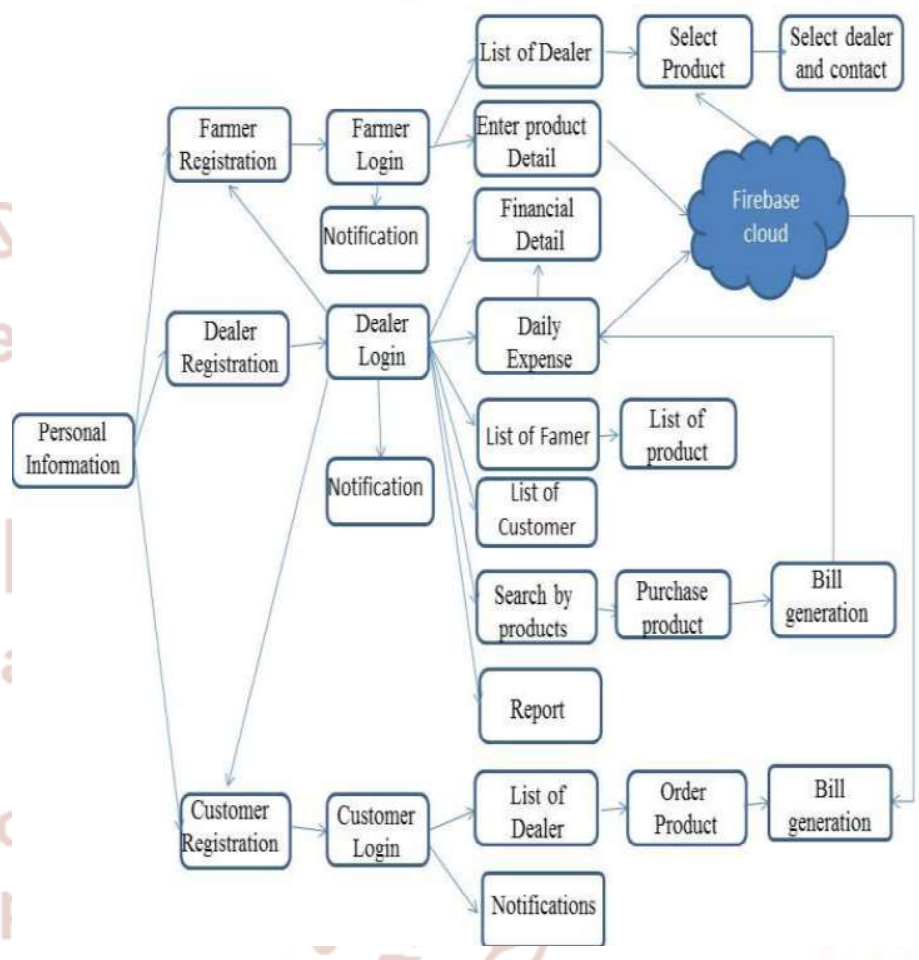

Fig. 1: Architecture Diagram of the Proposed System The proposed system is designed for three end users farmer, dealer and customer. This is the convenient platform for easy selling, dealing and purchasing of product.

The farmer will be able to add his product details and which will be stored on firebase cloud. List of product will be retrieved and sale product will be added on cloud.

List of dealers can be retrieved to continue with the selling activity, and notification will be send to the particular dealer of the available product of his interest. And finally report will be generated according to selling of the product from the cloud.

The Dealer can register his detail and login, After login the dealer will have dashboard which will consist of Financial detail, daily expense, list of farmer, list of customer, list of products and record. After getting the list of farmer he will be able to see all the already existing registered farmer and can see the availabily of product with detail, for buying the product, and can make the payment of farmer 
from financial detail. He can also get the list of already existing customer to sale his product and raise notification to them for payment. Dealers can maintain yearly, monthly, weekly and daily records. In daily expense all the daily payment details and daily spent are maintained.

The customer will be able to purchase the product from the particular dealer and send the notification to the dealers for the required product.

\section{ADVANTAGES}

Accuracy in accounting and billing system of farmers, dealers and customers.

$>$ Easy to use.

$>$ It saves time.

$>$ Quality of products is also maintained.

\section{APPLICATIONS}

$>$ The proposed system can be used by the general dealers, farmers, and customers of soft commodities products.

Multiple farmers, dealers and customer can use the system at the same time.

\section{MATHEMATICAL MODEL}

Let $\mathrm{S}$ be the set.

$\mathrm{S}=\{\mathrm{I}, \mathrm{F}, \mathrm{O}\}$

Where,

$\mathrm{I}=$ Input given by the user.

$\mathrm{F}$ is a set of function

$F=\{F 1, E 2, F 3, F 4, F 5, F 6, F 7, F 8, F 9, F 10, F 11$,

F12, F13, F14, F15, F16, F17, F18, F19, F20, F21\}

$\mathrm{F} 1=$ Registration of farmer, dealer or customer.

F2 $=$ Login of farmer, dealer or customer.

F3 $=$ Add product by farmer

$\mathrm{F} 4=$ List of available product at farmer's end.

F5 $=$ List of dealer

F6 = Report of farmer

F7 $=$ Financial Detail of farmer

F8 $=$ Farmer's notification

F9 $=$ Add product for sales by farmer

F10 $=$ Add product for sales by dealer

F11 $=$ List of available product at dealers end

$\mathrm{F} 12=$ List of registered farmer

F13 $=$ List of registered customer

$\mathrm{F} 14=$ Dealer's notification

F15 $=$ Dealer's report

F16 = Daily Expenses of dealer

F17 $=$ Purchase product from farmer
F18 $=$ Purchase product from dealer

F19 $=$ List of dealer

F20 $=$ Customer's notification

F21 $=$ Customer's report

$\mathrm{O}=$ Output generated after applying method (i.e Financial Balance Management).

\section{CONLCLUSION \& FUTURE WORK}

The aim of this proposed system is to help the general dealer, farmer and customer of fruit to buy fruits in minimum amount within minimum time.

We have studied the difficulties faced by farmer, dealer and customer of fruit, and to overcome their difficulties we are proposing an ERP system. This system will have some advance features which will be beneficial for them and which will make their work easy in the world of digitization.

\section{REFERENCES}

1. www.theinternationaljournal.org> RJSSM: Volume: 05, Number: 11, March 2016.

2. http://www.shreeshree.org/sabzimandisoftware

3. http://www.ebizframe.com

4. Data Mining Techniques: For Marketing, Sales and Customer Support

5. Sageerpx3_agricultureKPL.pdf

6. IOSR journal of mechanical and civil engineering (iosr-jmce) issn: 2278-1684 volume 3, issue 6 (nov. - dec. 2012), pp 49-91 www.iosrjournals.org

7. https://www.worldfinance.com/markets/technolog $\mathrm{y} /$ justcommodity-software-solutions-forcommodity-trading-and-risk-management.

8. https://softwareconnect.com/farm-accounting/dbcsmartsoftware-grainsmart.

9. Survey on Aspect-level Sentiment Analysis kimschouten.

10. A Survey on Sentence Level Sentiment Analysis.International Journal of Computer Science Trends and Technology (IJCST) Volume 3 Issue 3, May-June 2015.

11. Opinion mining of movie reviews at document level. International Journal on Information Theory (IJIT), Vol.3, No.3, July 2014 